\title{
STRUCTURAL DAMAGE IN MEXICO CITY
}

\author{
John F. Hall and James L. Beck
}

Earthquake Engineering Research Laboratory, California Institute of Technology

Abstract. This paper describes the structural damage in Mexico City caused by the September 19, 1985 earthquake. Photographs which illustrate various features of structural behavior are included. One explanation is presented as to why buildings with fundamental periods of elastic vibration considerably below the predominant twoaecond period of the ground motion were most vulnerable to damage.

\section{Introduction}

The September 19, 1985 earthquake caused considerable damage to modern construction in Mexico City, but only in those areas on the bed of an old lake because there the ground motion was considerably amplified (Beck and Hall, 1986). About 1000 buildings, mostly of masonry and reinforced concrete, were destroyed. Many more suffered moderate, but repairable, damage. A brief look at the effect of the earthquake on buildings in Mexico City is presented in this paper. Included is one explanation of why buildings with fundamental periods of elastic vibration considerably less than the predominant period of the lake-bed motions were damaged most severely.' The intrusion of this paper into a journal of geophysical research is intended to round out this special issue on the Mexican earthquake and to promote interaction between civil engineers and geophysicists.

\section{Overview of the Damage}

Most of the buildings that ouffered full or partial collapses probably lacked ductility, that is, the ability to undergo considerable yielding without looing strength. Since even most wellbuilt buildings yield during strong ground shaking, ductility is essential to avoid collapse, especially for long-duration earthquakes when a number of yield cycles occur. In reinforced concrete construction, proper detailing and placement of the ateel reinforcing bars is an important element in providing ductility. Perhaps with longer bar anchorages and extra hoops to confine the concrete, the school shown in Figure 1 would have survived the shaking.

In design, ductility is interrelated with strength because if the strength of a building is too low, then the ductility demanded by an earthquake is very high. In Mexico City, lack of strength was evident in the columns of many buildings (Figure 2), a violation of an important principle of seismic resistant design. This principle otates that proportioning columns to be stronger than the girders is essential to distri-

Copyright 1986 by the American Geophysical Union.

Paper number $6 \mathrm{~L} 6089$.

0094-8276/86/006L-6089\$03.00 bute the ductility demand throughout the building and avoid concentration of yielding in a single story.

Flat-plate construction, consisting of reinforced concrete columns and slabs without beams, did not fare well in the earthquake. One type of failure mode was caused by inadequate shear strength in the slab-to-column connections which resulted in pancake failures of the slabs with the columns remaining upright in some cases (Figure 3).

The use of unreinforced masonry to fill in exterior walls between reinforced concrete frames is a common construction practice in Mexico City. The masonry panels, being stiff, attracted a large share of the earthquake load and, being brittle, often failed. Diagonal cracks resulting from an overstress in shear are a characteristic of such failures (Figure 4). In addition, use of masonry infills on three sides of a building, while leaving the front open, created a nonsymmetric distribution of stiffness, causing a torsional response that increased the stress on the structural elements in the perimeter of the building.

Steel construction is rare in Mexico City, yet one of the most spectacular examples of damage occurred to the complex of five steel-frame buildings at Conjunto Pino Suarez. A 21-story tower overturned at the 3 rd floor level and fell to the south onto another tower of 14 stories (Figure 5). A clue to the collapse mechanism was obtained after the neighboring identical 21-story tower (background of Figure 5) was stripped revealing buckled columns on its southern column line at the 3 rd story. These were steel box columns, and their plates separated at the welds.

An interesting characteristic of the damage in Mexico City is that a great number of buildings

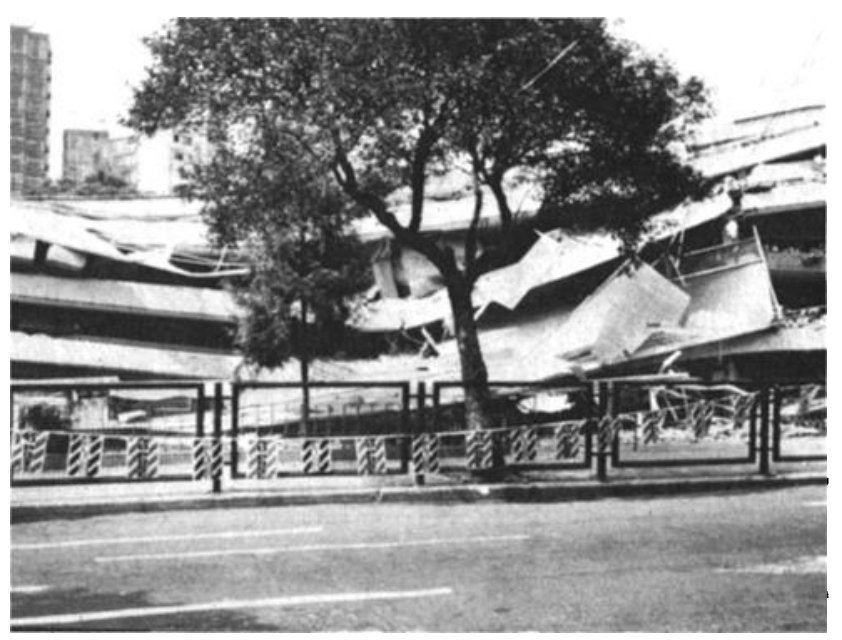

Fig. 1. Collapsed school. 


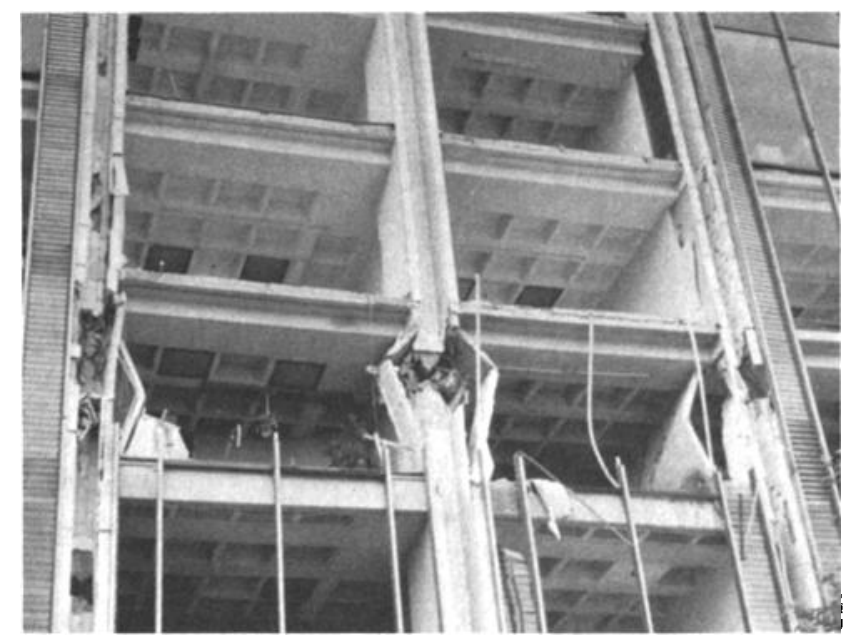

Fig. 2. Weak columns.

collapsed in their upper stories, leaving the lower portion intact (Figure 6). One possible reason for this behavior is that deaigners tapered the column sizes severely in the upper stories, permisoible if only gravity and wind loads act, but unwise for earthquake loads. Another possibility is through impact between two buildings of different heights, spaced closely together (Figure 7).

Although most of the damage occurred to superstructures, there were some foundation failures. Those multistory buildings in Mexico City founder on piles that were not long enough to bear on th. firm stratum below the soft clay layer may have olipped downward during the earthquake. This may be why the building shown in Figure 8 tilted.

\section{Discussion of the Damage}

The predominant two-second period in the ground motion recorded at the SCT site on the lake bed (Beck and Hall, 1986) suggests that structures with fundamental periods of elastic vibration of around two seconde should be particularly hard hit due to resonance. However, this is an oversimplification because most

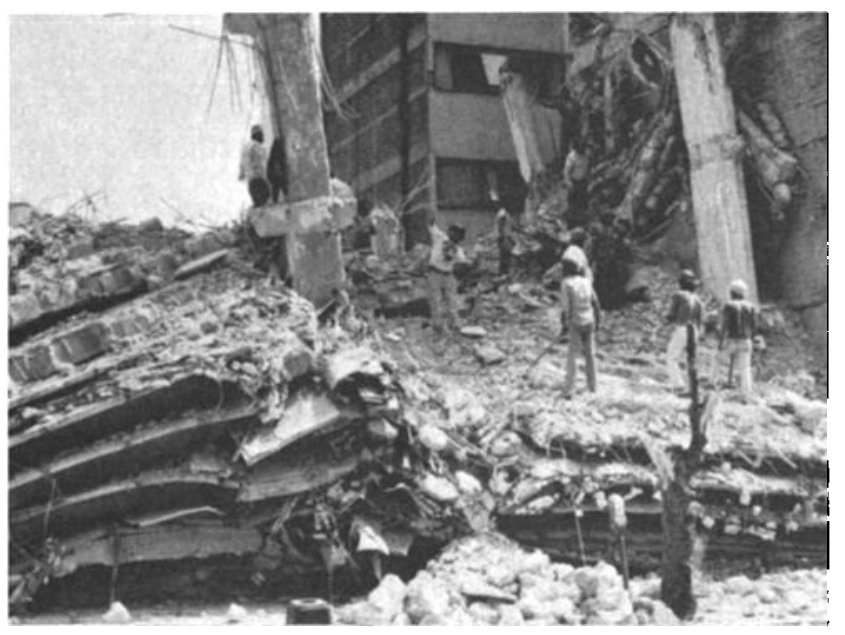

Fig. 3. Flat plate construction.

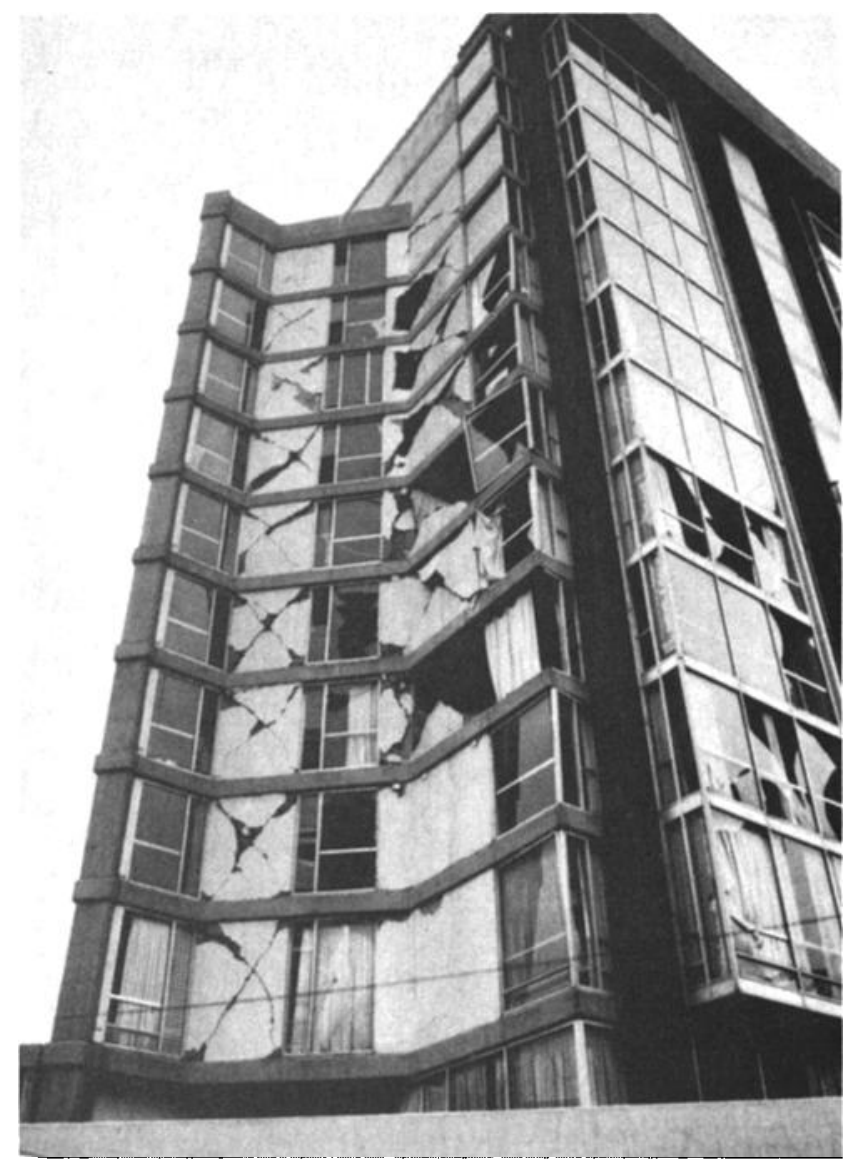

Fig. 4. Cracked masonry infills.

buildings do not behave elastically during strong ground shaking as economics prevents them from being designed to do so. As a structure yields (begins to ouffer damage), it softens, and its effective period of vibration lengthens. Thus, a building having an elastic period of two seconds or more may move away from being in resonance with the ground shaking as its response increases. On the other hand, a building having a shorter period of elastic vibration may move into

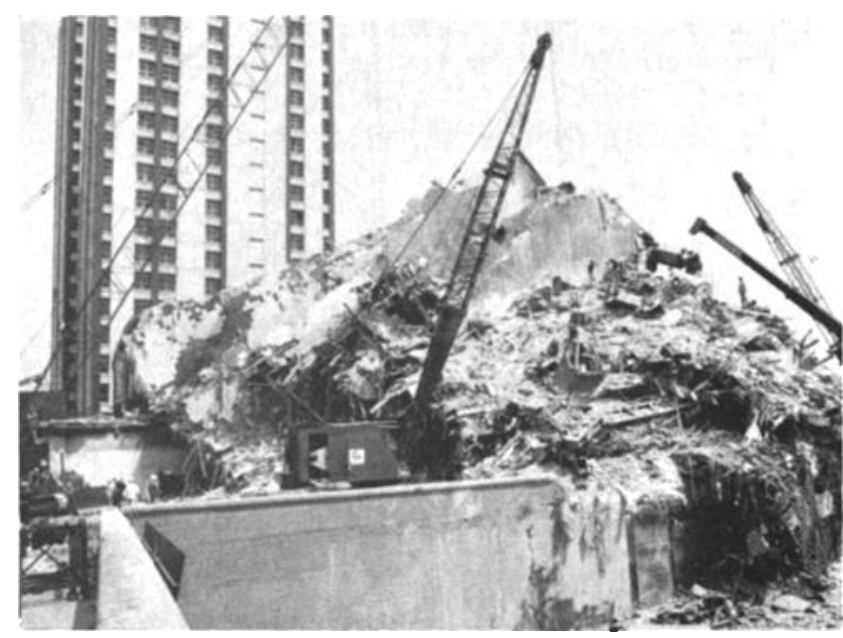

Fig. 5. Toppled tower at Pino Suarez. 


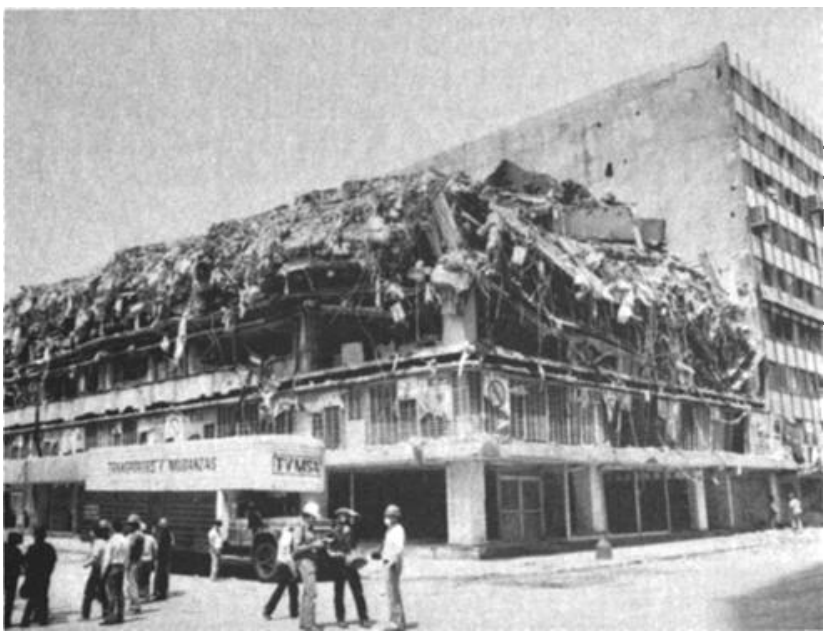

Fig. 6. Upper story collapse.

a resonance condition as it yields. Indeed, the most vulnerable buildings in Mexico City were those in the 6 to 15 story range; about $20 \%$ of these that were located in the area of damage either collapsed or were severely damaged. Since N-story buildinga have, in Mexico City, a fundamental period of elastic vibration of about N/10 seconds (Robayashi et al., 1986), periods of the most vulnerable buildings ranged roughly from $1 / 2$ to $1-1 / 2$ seconds.

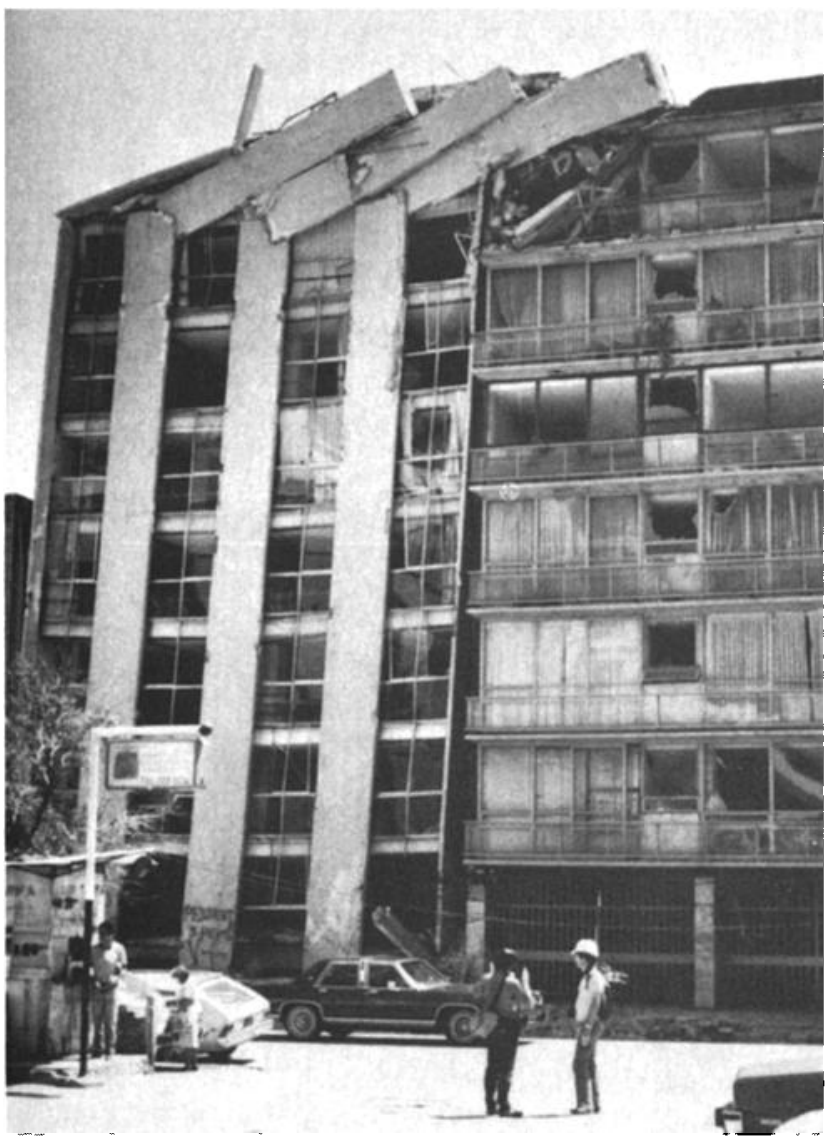

Fig. 7. Impact damage.
The effect that yielding has on the seimmic attack a structure receives can be demonstrated by a time-history analysis using an elasticplastic, hysteretic model. Consider set of buildings from 2 to 40 stories which meets the seismic provisions of the building code in Mexico City. By this code, the strength of the building must be sufficient to resist a set of forces acting at the floor levels equivalent to the inertia forces produced by vibration of the building in a linear deformation shape. The sum of these design forces equals the product of the building weight and a seismic coefficient of 0.06 (independent of $\mathrm{N}$ ) and a design load factor of, say, 1.2. Assume the structure vibrates in a single, linear deformation shape with elastic period of vibration of $\mathrm{N} / 10$ seconds and elasticplastic force-diaplacement relation. Introduce an overstrength factor to enable a two-story building to behave elastically without yielding since this agrees with the evidence. Analysis shows that a factor of 2.7 will suffice when the input is taken as the SCT east-west ground motion. Postulate a decrease in the overstrength factor with building height according to $1+3.4 / N$. Such a relationship is reasonable because short buildings are often bearing wall structures which can be considerably otronger than the code requires, while tall buildings are beam-column frame strucures, often with masonry infills, which have relatively much less reserve strength.

Resulta from time-history analyses for the SCT

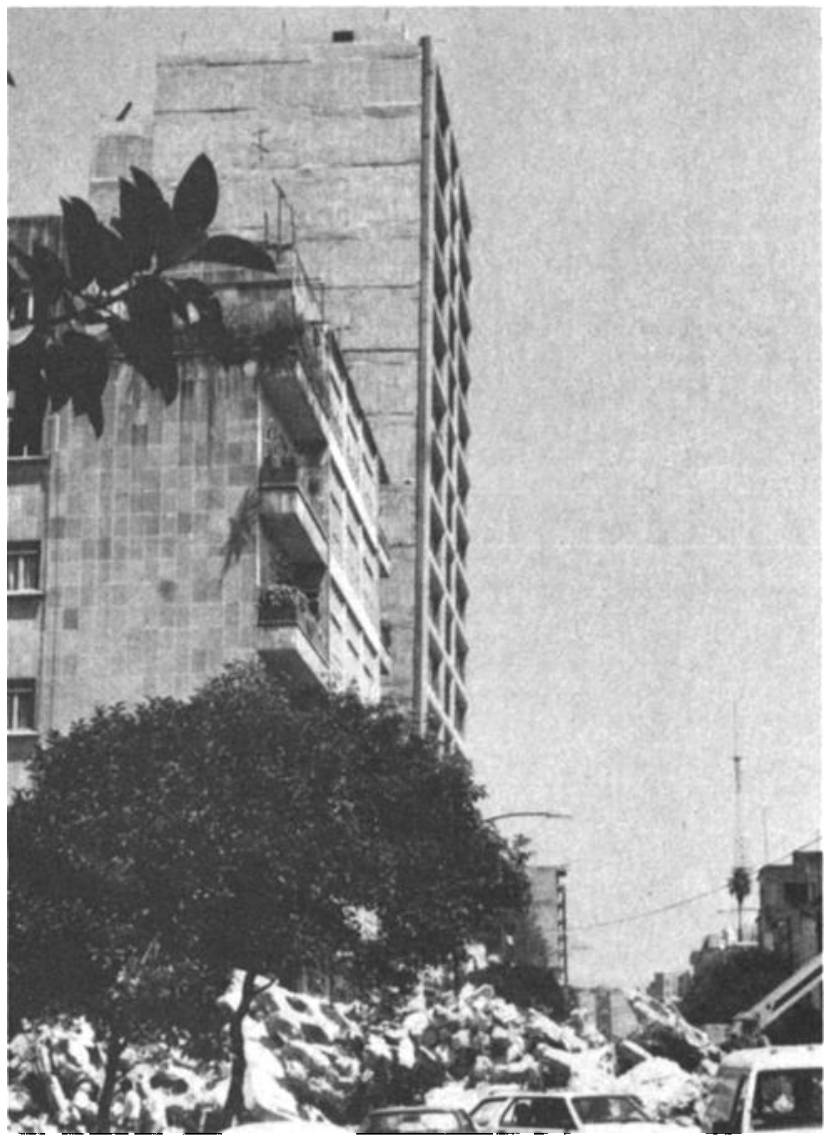

Fig. 8. Foundation failure. 

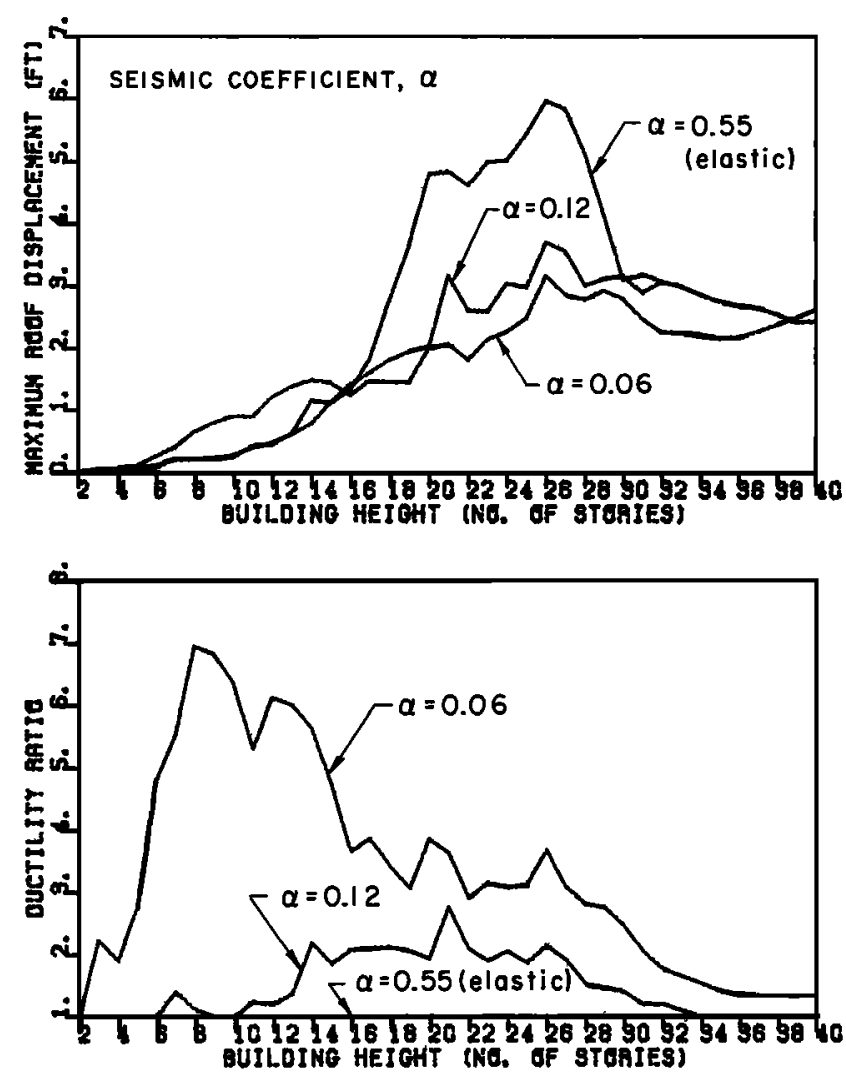

Fig. 9. Building responses computed for the SCT east-west ground motion.

east-west input are presented in Figure 9 (maximum roof displacement vs. building height and ductility ratio vs. building height) for three designs based on seismic coefficients of 0.06 (as in the Mexico City code), 0.12 , and 0.55 (a value sufficiently high so that no yielding occurs). The ductility ratio, or ductility demand, is the maximum roof displacement experienced during the earthquake divided by the roof displacement at which yielding commences. If no yielding occurs, the ductility ratio is defined to be unity.

The elastic response (Figure 9, top) shows a considerable resonance for buildings 20 to 25 stories in height due to the coincidence of their elastic vibration periods with the predominant period range in the ground motion input. For buildings designed with lower seismic coefficients $(0.06$ or 0.12$)$, this resonance disappears due to the lengthening of the building period as yielding takes place.

The seismic attack on the building is best measured in terms of ductility demand (Figure 9, bottom). The demand is highest for buildings 6 to 15 stories in height. Apparently, yielding has moved the 6 to 15 story buildings into a resonance condition (relative to the yield displacement) and moved taller buildings away. The ductility ratio requirement of 5 to 7 as shown by the analysis can be met with good design and detailing practices, but could cause considerable trouble otherwise, especially for earthquakes of long duration which produce many cycles of yielding. Increasing the seismic coefficient to 0.12 greatly reduces the ductility demand. The post-earthquake code in Mexico City now has essentially this seismic coefficient (Rosenblueth and Meli, 1986).

Although the analysis correctly predicts the height range of the most vulnerable buildings, the ductility ratios given in Figure 9 and mentioned above should be interpreted with caution due to the many assumptions made. For example, soil-structure interaction and nonlinear soil softening have been neglected; the many degrees of freedom of a real structure have been replaced by a single, linear deformation shape; and uniform yielding throughout the building has been assumed. However, the analysis does capture an essential characteristic of the nonlinear response, suggesting why the damage was concentrated in buildings with fundamental periods of elastic vibration significantly less than the two-second predominant period of the lake-bed motion.

\section{Concluding Remarks}

Even in the severely damaged areas of Mexico City, many buildings survived undamaged, some without even a broken pane of glass. Why did some buildings fare well while others suffered? Were building collapses due to gaps in engineering knowledge or to sloppy design or construction? Is the building code adequate? These questions remain partially unanswered. While general analyses such as presented in the previous section help, full resolution of these questions awaits studies of individual buildings. Unfortunately, a lack of detailed documentation of the damage following the earthquake, the subsequent demolition and removal of many buildings without inspection or material testing, and the difficulty of gaining access to the structural plans of the buildings may prevent these questions from ever being completely resolved.

\section{References}

Beck, J.L. and J.F. Hall, Factors contributing to the catastrophe in Mexico City during the earthquake of September 19, 1985, Geophys. Res. Letters, this issue.

Kobayashi, Ho, K. Seo and S. Midorikawa, Report on seismic microzoning studies of the Mexico City earthquake of September 19, 1985, Part 2, Tokyo Institute of Technology, Yokohama, Japan, Feb. 1986.

Rosenblueth, E. and R. Meli, The 1985 earthquake: causes and effects in Mexico City, Concrete International, American Concrete Institute, May 1986.

J. L. Beck and J. F. Hal1, Earthquake Engineering Research Laboratory, Caltech, Pasadena, CA 91125

(Received February 28, 1986 accepted April 22, 1986 .) 